\title{
Penerapan Teknologi Cloud Computing Untuk Aplikasi Repository Data Di Universitas Muhammadiyah Gorontalo
}

\author{
Nursetia Wati, S.SI, M.Kom ${ }^{1}$, Rizal Lamusu, S.Kom, M.T ${ }^{2}$ \\ ${ }^{1}$ e-mail: nursetiawati@umgo.ac.id, 2,rizal_lamusu@umgo.ac.id. \\ ${ }^{1}$ Ketua Peneliti, Universitas Muhammadiayah Gorontalo, Program Studi SIstem Informasi \\ 2, Anggota Peneliti, Universitas Muhammadiayah Gorontalo, Program Studi SIstem Informasi
}

\begin{abstract}
Current technological developments have supported all needs and requests for information for each individual through the creation of information presentation media, which is used to convey information as desired. In utilizing the technological development itself, researchers intend to apply Cloud Computing technology for data repositories at University of Muhammadiyah Gorontalo.Repository of this data is expected to help the performance of Academic and Supporting Staff and Students in the University of Muhammadiyah Gorontalo. The aim of this research is to be able to apply Cloud Computing technology for database repository applications so that it can help Lecturers and Academic Support Staff and Students for administrative and other purposes that can be stored in a database or file for later distribution using a computer network. This study conducted a stage that began by surveying whether the Muhammadiyah University of Gorontalo had applied this Cloud Computing technology to this data repository, then collected the data needed to create a Repository system. The output of this system was a Repository system containing data from Academic and Academic Support Staff and students at Muhammadiyah University, Gorontalo.
\end{abstract}

\section{Keywords: Cloud Computing, Repository, Data, University of Muhammadiyah Gorontalo \\ Intisari}

Perkembangan teknologi saat ini sudah mendukung segala kebutuhan dan permintaan akan informasi bagi setiap individu melalui penciptaan media penyajian informasi, yang digunakan untuk menyampaikan informasi sesuai dengan yang diinginkan. Dalam memanfaatkan perkebangan teknologi itu sendiri peneliti berkeinginan dalam menerapkan teknologi Cloud Computing untuk repositorydata di Universitas Muhammadiyah Gorontalo.Repository data ini diharapkan dapat membantu kinerja Dosen dan Tenaga Penunjang Akademik serta Mahasiswa dalam lingkungan Universitas Muhammadiyah Gorontalo. Tujuandari penelitian ini adalah dapat menerapkan teknologi Cloud Komputing untuk aplikasi Repository datasehingga dapat membantu Dosen dan Tenaga Penunjang Akademik serta Mahasiswa demi kepentingan admistrasi dan lainnya yang dapat disimpan pada suatu database atau file untuk kemudian didistribusikan dengan menggunakan jaringan komputer. Penelitian ini melakukan tahapan yang dimulai dengan mensurvei apakah pada Universitas Muhammadiyah Gorontalo sudah menerapkan teknologi Cloud Komputing ini pada repository data ini, kemudian dikumpulkan data yang diperlukan untuk membuat sistem Repository.Keluaran dari sistem ini adalah sistem Repository yang berisikan tentang data Dosen dan Tenaga Penunjang Akademik serta Mahasiswa yang ada di Universitas Muhammadiyah Gorontalo.

Kata Kunci : Cloud Computing, Repository, Data, Unversitas Muhammadiyah Gorontalo

\section{PENDAHULUAN}

Teknologi Cloud Computing mungkin masih kurang terdengar di lingkungan sehari-hari, tapi lebih daripada itu, Teknologi ini sebenarnya sudah sering digunakan dalam kehidupan sehari-hari. Cloud Computing dapat didefinisikan juga komputasi awan yang memili arti Cloud computing can be defined as simply the sharing and use of applications and resources of a network environment to get work done without concern about ownership and management of the network's resources and applications. With cloud computing, computer resources for getting work done and their data are no longer stored on one's personal computer, but are hosted elsewhere to be made accessible in any location and at any time [1]. Repository data berfungsi sebagai suatu tempat penyimpanan dan pemeliharaan data. Sebuah repository juga dapat berupa tempat dimana database atau file disimpan untuk 
kemudian didistribusikan dengan menggunakan jaringan komputer atau internet. Repository berfungsi untuk mengumpulkan dan menyebarkan suatu data dalam bentuk digital [2], Repository adalah pusat lokasi untuk mencari dan mengakses informasi dari berbagai sumber seperti internet, intranet, perusahaan, database dan berbagai system penyimpanan file, yang secara efesien dan cepat dapat mendistribusikan informasi.

Sedangkan Repository adalah kumpulan pengetahuan internal dan eksternal di dalam lokasi tertentu untuk lebih efisien dalam hal penggunaannya bagi manajemen di dalam sebuah organisasi [3].

Universitas Muhammadiyah Gorontalo merupakan salah satu institusi perguruan tinggi yang memiliki cukup banyak jumlah Dosen, Tenaga Penunjang Akademik dan Mahasiswanya.Penelitian ini diharapkan dapat menjadi solusi untuk Memudahkan pengolahan data secara digital.Luaran pada penitian ini yaitu suatu aplikasi yang dapat menangani penyimpanan secara digital, selain itu dapat memudahkan dalam pencarian data yang telah dibuat dengan sebuah sistem yang dinamakan sistem repository data Dosen, Tenaga Penunjang Akademik dan Mahasiswa.

\section{METODOLOGI PENELITIAN}

Pada penelitian ini dilakukan pendekatan menggunakan metodologi pengembangan sistem model Prototyping.

Prototype adalah sebuah proses yang memungkinkan pengembang dapat mencipta model dari perangkat lunak yang akan dibuat [4]. Model ini dapat berbentuk prototipe dokumen, kerja atau program.Prototipe dokumen menggambarkan interaksi manusia-mesin sedemikian rupa sehingga costumer memahami pemakaian dan fungsi perangkat lunak tersebut.Prototipe kerja adalah implementasi sebagian dari fungsi perangkat lunak. Sedangkan prototipe program adalah implementasi semua fungsi program tetapi dengan antarmuka yang sederhana.

Tahapan-tahapan metode Prototype adalah :

1. Komunikasi dan pengumpulan kebutuhan.

Prototipe dimulai dengan identifikasi kebutuhan-kebutuhan costumer. Pengembang dan costumer harus sepakat dengan tujuan umum perangkat lunak.

2. Desain cepat.

Desain ini berfokus pada representasi tujuan perangkat lunak secara sederhana yang dapat dipahami oleh costumer seperti penyajian masukkan dan keluaran perangkat lunak.

3. Pembentukan prototype.

Hasil dari desain cepat menjadi acuan seorang pengembang untuk membuat prototipe dan selanjutnya akan dievaluasi oleh costumer.

4. Evaluasi dan perbaikan.

Prototipe akan dievaluasi oleh costumer dan dipakai untuk merinci kebutuhan terhadap perangkat lunak. Iterasi akan terjadi berulang kali sehingga prototipe ini akan memuaskan costumer. Pada saat yang sama, pengembang dapat lebih memahami kebutuhan costumer dan memperbaiki perangkat lunak itu sendiri.

5. Rekayasa Produk

Pemrograman prototipe dibuat oleh pengembang secara cepat untuk kemudian diperbaiki.Yang penting pada saat prototyiping, program dapat berjalan terlebih dahulu.Prototipe sering dipandang sebagai sistem yang pertama yang kemudian diperbaiki atau dibuang, digantikan yang lebih baik dengan memakai bahan-bahan yang ada dalam prototype. 
JTII, Vol. 4, No. 2, Bulan November 2019

Penerapan Teknologi Cloud...

ISSN 2502-1613/E-ISSN 2541-3740

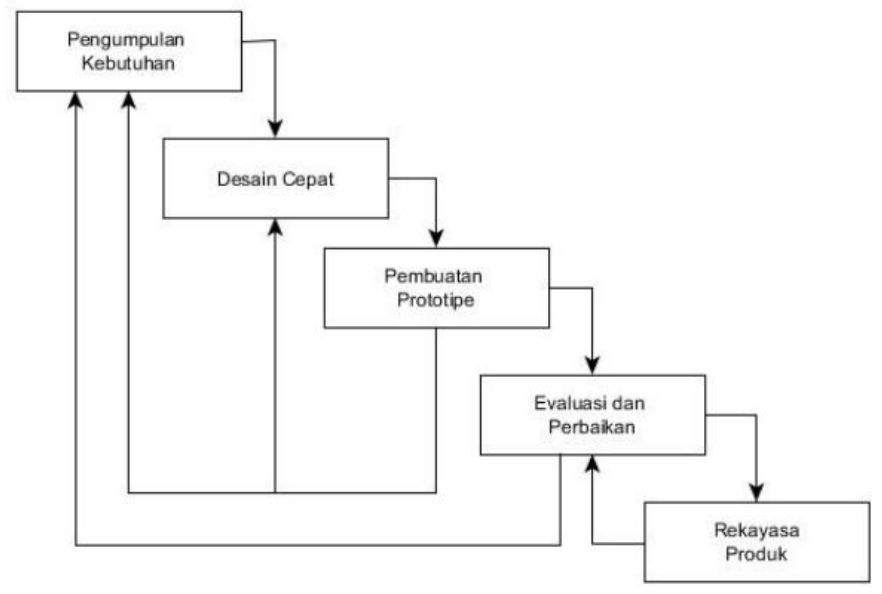

Gambar 1. Tahapan Penelitian

73 
a. Desain Alur Sistem

1. Diagram Konteks

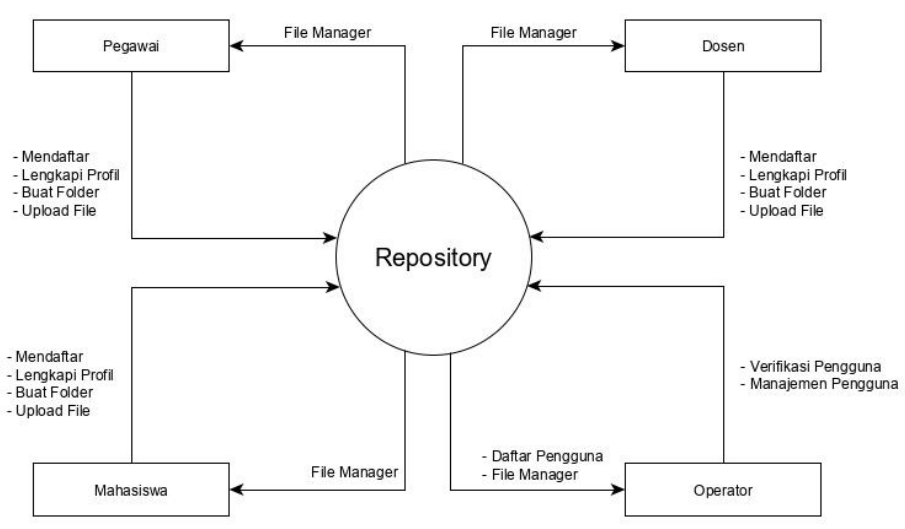

Gambar 2. Diagram Konteks

2. Diagram Berjenjang

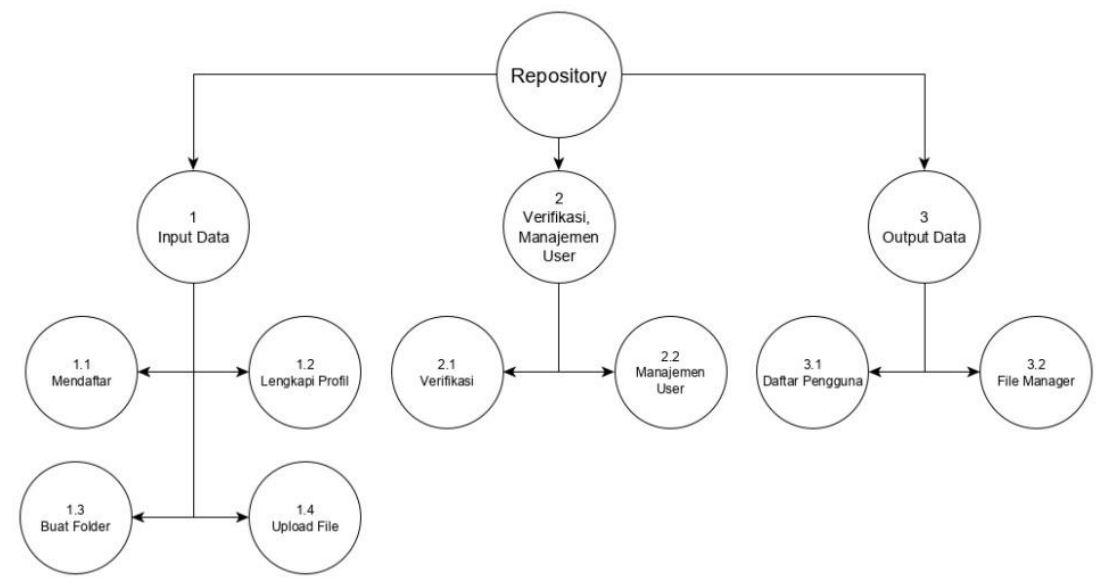

Gambar 3. Digram Berjenjang

3. Diagram Alir Data (DAD Lever 0) 


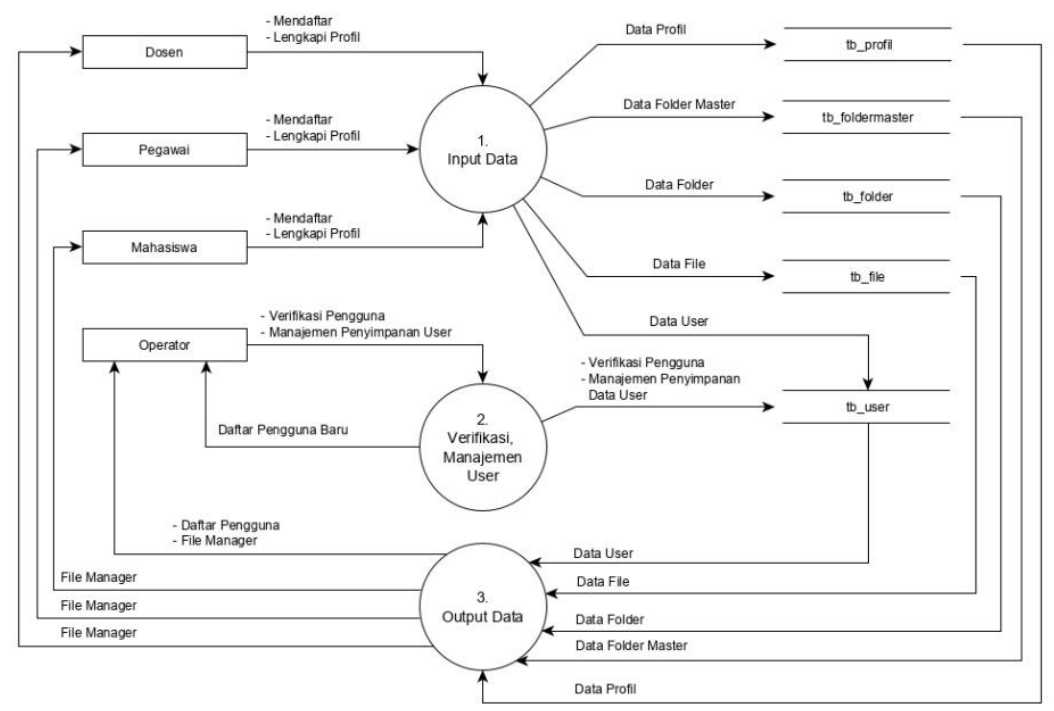

Gambar 4. Diagram Alir Data (DAD Level 0)

1. Tampilan Form Login

Fungsi dari form login yaitu untuk masuk pada aplikasi repository pada form ini terbagi dua level yaitu level admin atau Super user yang dimana hanya satu orang bertugas untuk memverifikasi pengguna baru sedangkan pengguna atau user merupakan dosen, pegawai dan mahasiswa.

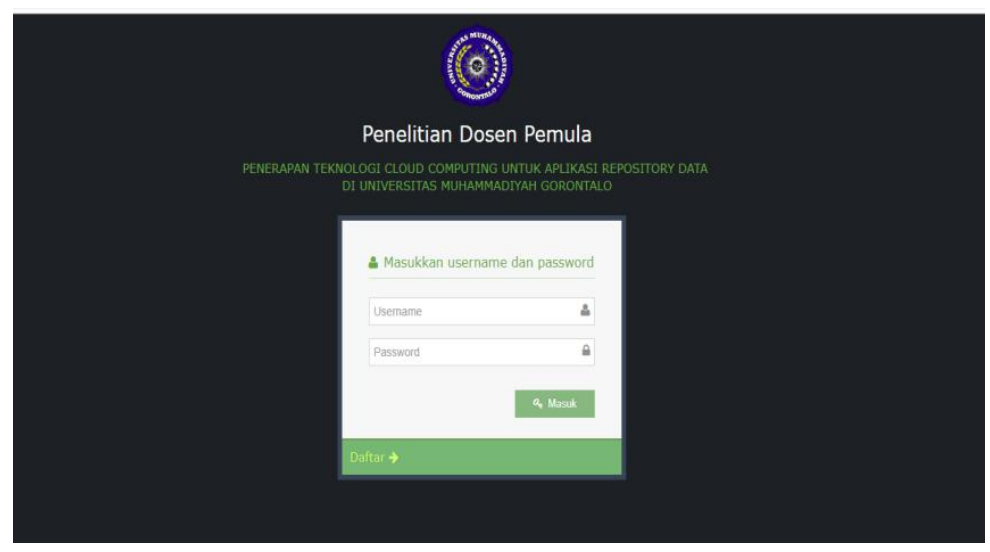

\section{Gambar 5. Tampilan Form Login}

2. Tampilan Form Daftar

Fungsi dari form daftar yaitu untuk mendapatkan nama pengguna dan password untuk dapat menjalankan aplikasi repository seperti terlihat pada gambar dibawah ini, pengguna harus mengisi terlebih dahulu data data yang diperlukan. 


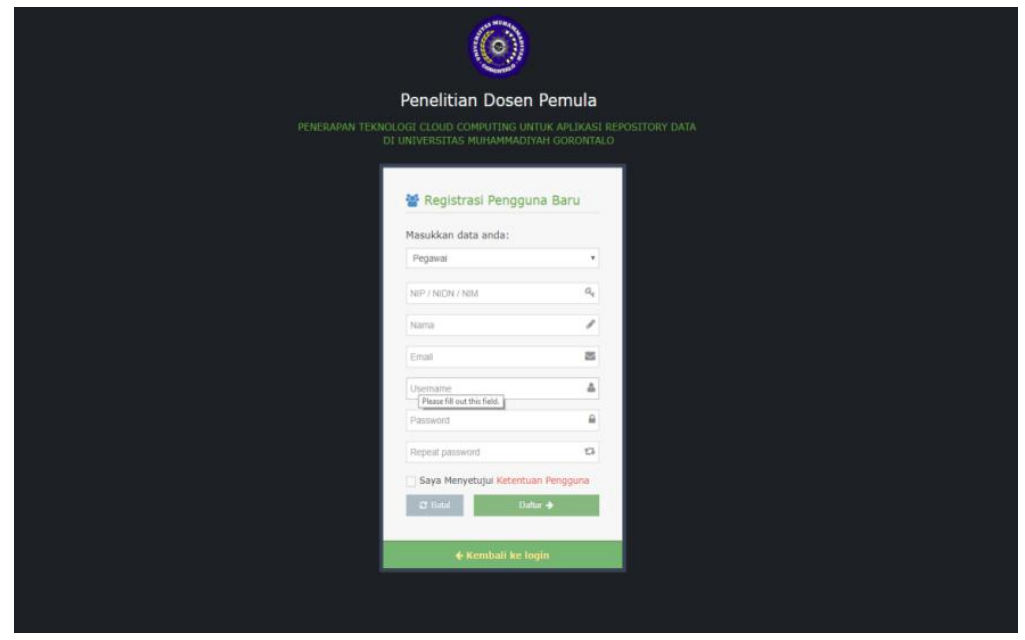

\section{Gambar 6. Tampilan Form Daftar}

3. Tampilan Form

Pengguna yang belum terverifikasi dan memverifikasi Pengguna oleh Superadmin.

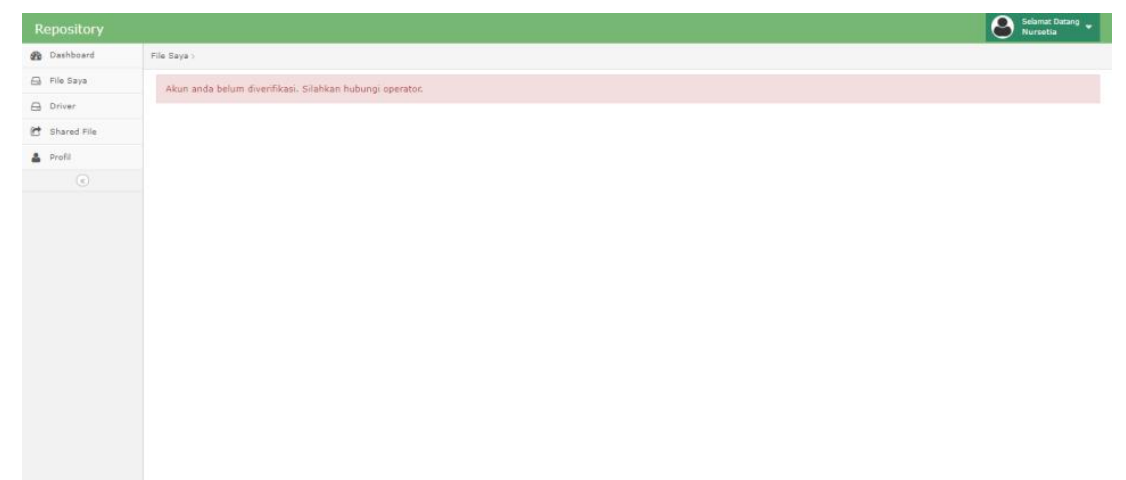

Gambar 7.

Pengguna Yang Belum Terverifikasi

Tampilan Form

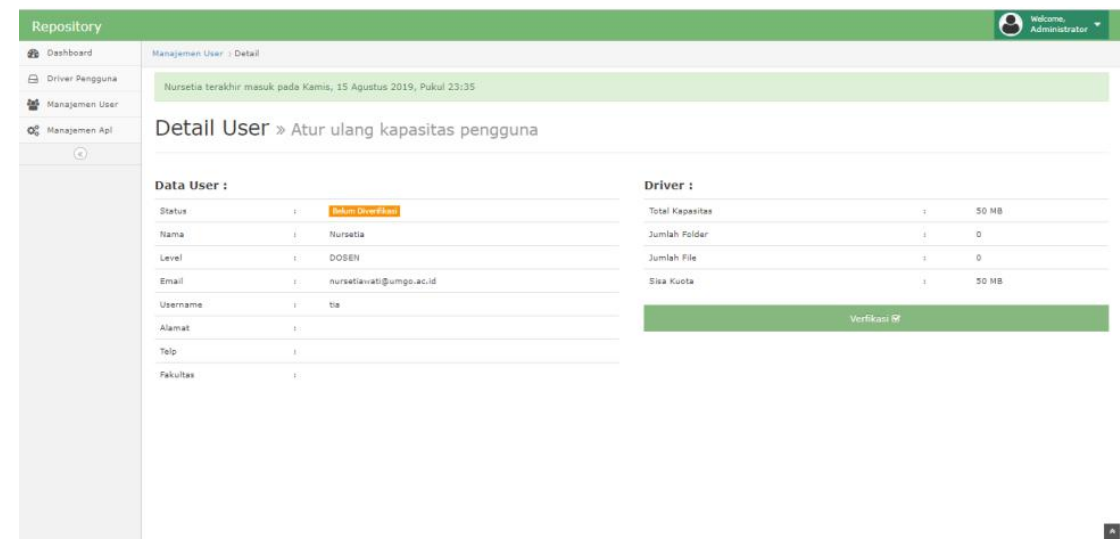

Gambar 8.

\section{Pengguna Oleh Superuser}

- Memverifikasi

4. Tampilan Form File Saya

Pada form ini Pengguna dapat melakukan tambah folder dan file serta biasa mengganti nama folder dan file bahkan bias menghapus folder atau file. 
Gambar 9.

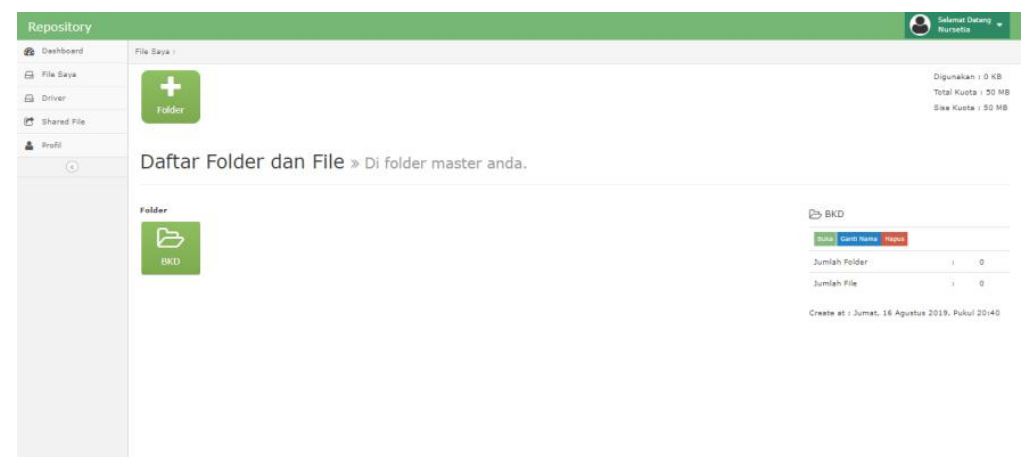

Saya

Tampilan Form File

5. Tampilan Form Shared File

Pada form ini pengguna dapat melihat file apa saja yang telah dibagikan kepada pengguna dari pengguna lainnya. Dan untuk membagikan file pengguna/user bisa masuk ke menu file saya dan pilih salah satu folder yang tersimpan file yang akan dibagikan, kemudain saat klik tombol buka akan ditampilkan daftar folder dan file yang sudah disimpan dan bisa di bagikan dengan mengklik tombol shared pada tabel aksi, kemudian pengguna/user bisa memilih pengguna mana yang akan di bagikan file tersebut, seperti gambar berikut.

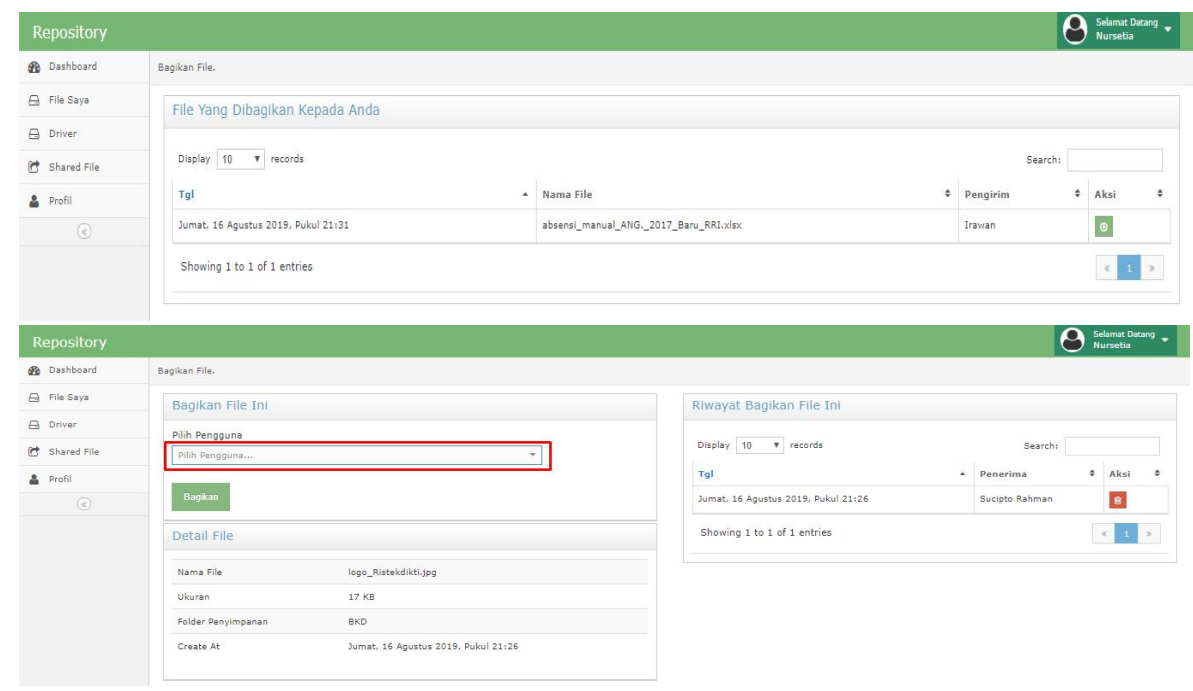

Gambar10. Tampilan Form Shared File

\section{b. Evaluasi dan Perbaikan}

Pengujian terhadap program yang dibuat menggunakan blackbox testing yang fokus terhadap proses masukan dan keluaran program [5], yang bertujuan untuk menegecek apakah fungsi/ Method yang digunakan berjalan sesuai dengan apa yang diharapakan, dan berikut merupakan keterangan dari pengujian tersebut: 
Tabel 1. Pengujian Sistem Menggunakan BlackBox

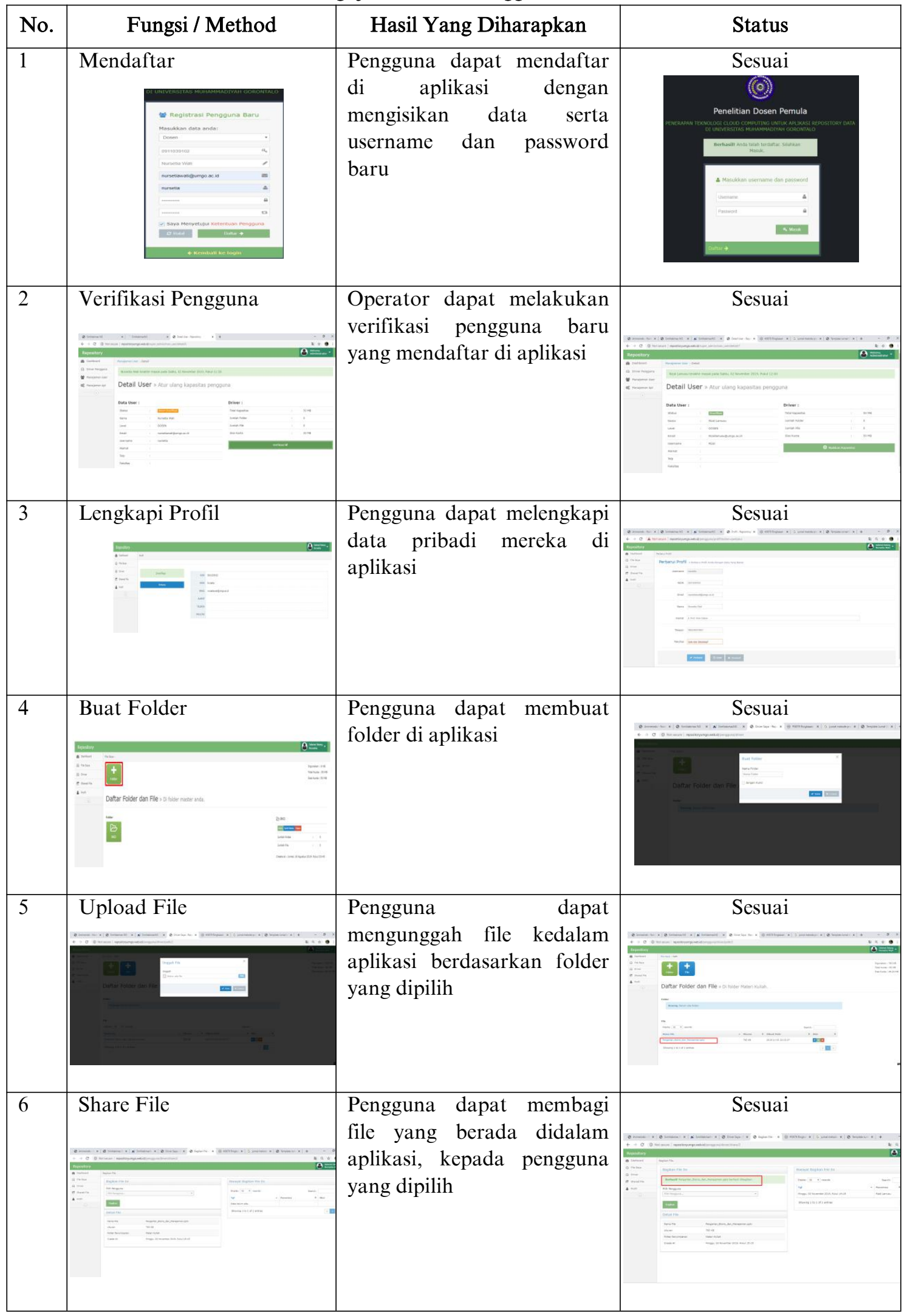




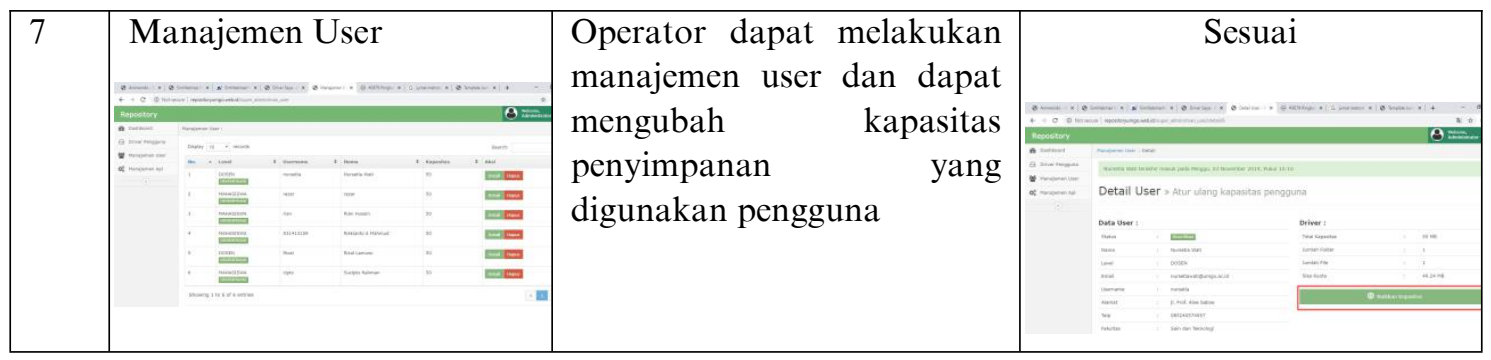

\section{c. Alur Sistem}

1. Pengguna mendaftar disistem dengan memasukkan data username, email, password baru.

2. Operator melakukan verifikasi terhadap pengguna baru yang mendaftar di aplikasi, dengan mempertimbangkan level user dan data pribadi pengguna baru.

3. Masing-masing user yang telah di verifikasi, sistem akan langsung otomatis membuatkan path driver didalam server yang dapat digunakan untuk mengelolah file dan folder pengguna berdasarkan kapasitas yang telah ditentukan (50 MB dibuat otomatis oleh sistem)

4. Setelah pengguna telah di verifikasi, pengguna dapat langsung masuk ke aplikasi menggunakan username dan password yang dipakai saat mendaftar.

5. Pengguna dapat melengkapi data pribadi atau profil pengguna dengan menggunakan tombol profil

6. Pengguna dapat mengelolah path driver yang telah dibuat oleh sistem seperti membuat folder dan mengunggah file.

7. Pengguna dapat membagi data atau file yang diunggah kedalam sistem kepada sesama pengguna yang telah terdaftar di aplikasi

8. Operator dapat melakukan manajemen user yaitu menghapus user dan menaikkan maupun menurunkan kapasitas penyimpanan pengguna.

\section{KESIMPULAN}

Adapun Hasil Dari Penelitian Ini Disimpulkan Bahwa Penerapan Teknologi Cloud Computing Untuk Aplikasi Repository Data Di Universitas Muhammadiyah Gorontalo ini dapat dijabarkan sebagai barikut:

1. Aplikasi Repository Data di Universitas Muhammadiya Gorontalo dapat memudahkan Pengolahan Data Secara Digital.

2. Aplikasi Repository Ini Juga Dapat Melakukan Penyimpanan Secara Digital.

3. Dapat Memudahkan Dalam Pencarian Data Yang Telah Dibuat Dengan Sebuah Sistem Yang Dinamakan Sistem Repository Data Dosen, Tenaga Penunjang Akademik Dan Mahasiswa.

4. Dapat Melakukan Shared Data Yang Dibutuhkan Dilingkungan Universitas Muhammadiyah Gorontalo.

\section{REFERENSI}

[1] Akhmad Syaikhu: KOMPUTASI AWAN (CLOUD COMPUTING) PERPUSTAKAAN PERTANIAN

[2] Ricky, Michael Yoseph (2012).PENGEMBANGAN APLIKASI ONLINE MOBILE REPOSITORY.Teknik informatika, Ilmu Komputer, binus Universitas

[3] Tittel, ED. (2002). Computer Networking.1st Edition.Mcgraw Hill / Osborne, California.

[4] Purnomo, H., dan Zacharlas, T. 2005. Pengenalan Informatika Perspektif Teknik dan Lingkungan. Yogyakarta :Andi.

[5] Mirantina Novi, (2017). Sistem Informasi Pemesanan Barang Pada La Grande Mustafa Pontiana. Program Studi Manajemen Informatika Amik Bsi Pontianak. 